\title{
Relationship between cardiovascular risk factors and biomarkers with necrotic core and atheroma size: a serial intravascular ultrasound radiofrequency data analysis
}

\author{
Héctor M. García-García • Volker Klauss • Nieves Gonzalo • \\ Scot Garg • Yoshinobu Onuma • Christian W. Hamm • \\ William Wijns • Jennifer Shannon • Patrick W. Serruys
}

Received: 15 November 2010/Accepted: 29 April 2011/Published online: 19 May 2011

(C) The Author(s) 2011. This article is published with open access at Springerlink.com

\begin{abstract}
We explored the impact of patient demographics, anthropometric measurements, cardiovascular risk factors, and soluble biomarkers on necrotic core and atheroma size in patients with coronary disease. The IBIS-2 trial enrolled 330 patients. In the multivariate analysis, at baseline, creatinine had a positive, whereas baseline mean lumen diameter and myeloperoxidase had a negative, independent association with percentage of necrotic core (PNC); while age, glomerular filtration rate $<60, \mathrm{HbA} 1 \mathrm{c}$, previous $\mathrm{PCI}$ or $\mathrm{CABG}$ and baseline \% diameter stenosis were
\end{abstract}

For the IBIS-2 Investigators.

H. M. García-García $(\bowtie) \cdot$ N. Gonzalo .

S. Garg · Y. Onuma · P. W. Serruys

Thoraxcenter, Erasmus MC, Ba583, 's-Gravendijkwal

230, 3015 CE Rotterdam, The Netherlands

e-mail: h.garciagarcia@erasmusmc.nl

H. M. García-García

Cardialysis, Rotterdam, The Netherlands

V. Klauss

Campus Innenstadt University Hospital Munich,

Munich, Germany

C. W. Hamm

Kerckhoff Klinik, Bad Nauheim, Germany

W. Wijns

Cardiovascular Center, Aalst, Belgium

J. Shannon

GlaxoSmithKline, RTP, Durham, NC, USA positively, and acute coronary syndromes (ACS) were negatively associated with baseline percentage atheroma volume (PAV). The variables associated with a decrease in PNC from baseline were darapladib, ACS and a large content of NC at baseline, while variables associated with an increase in PNC were previous stroke and \% diameter stenosis at baseline. Those variables associated with a decrease in PAV from baseline were waist circumference, statin use, CD40L and baseline PAV, while the only variable associated with an increase in PAV was baseline diastolic blood pressure. Treatment with darapladib was associated with a decrease in necrotic core, but was not associated with a decrease in percentage atheroma volume. On the contrary, statin use was only associated with a decrease in percentage atheroma volume.

Keywords Atherosclerosis - Necrotic core · IVUS backscattering radiofrequency data analysis

$\begin{array}{ll}\text { Abbreviations } \\ \text { ACS } & \text { Acute coronary syndrome } \\ \text { CI } & \text { Confidence interval } \\ \text { CD-40L } & \text { CD40 ligand } \\ \text { CHD } & \text { Coronary heart disease } \\ \text { Cr } & \text { Creatinine } \\ \text { CSA } & \text { Cross-sectional area } \\ \text { hs-CRP } & \text { High sensitivity C-reactive protein } \\ \text { ICAM-1 } & \text { Intercellular adhesion molecule-1 } \\ \text { IL-6 } & \text { Interleukin-6 }\end{array}$




$\begin{array}{ll}\text { IVUS } & \text { Intravascular ultrasound } \\ \text { Lp-PLA2 } & \text { Lipoprotein-associated phospholipase } \\ & \text { A2 } \\ \text { Lyso-PC } & \text { lysophosphatidylcholine } \\ \text { MACE } & \text { Major adverse cardiovascular events } \\ \text { mmol } & \text { Millimoles } \\ \text { MMP-9 } & \text { Matrix metalloproteinase-9 } \\ \text { MPO } & \text { Myeloperoxidase } \\ \text { NC } & \text { Necrotic core } \\ \text { OxPL/apoB } & \text { Oxidised phospholipid per } \\ & \text { apolipoprotein B } \\ \text { PAV } & \text { Percent atheroma volume } \\ \text { RF } & \text { Radiofrequency } \\ \text { SBP } & \text { Systolic blood pressure } \\ \text { TCFA } & \text { Thin cap fibroatheroma }\end{array}$

\section{Introduction}

Cardiovascular (CV) disease remains the principal cause of death worldwide, with three-fourths of CV deaths attributed to atherosclerosis. Pathological studies in patients who have died from coronary heart disease (CHD) show extensive evidence of coronary atherosclerosis [1]. The current paradigm suggests that the main cause of cardiac death is primarily due to rupture of an advanced atherosclerotic lesion [2]. Ruptured plaques contain the largest amount of necrotic core (NC) among atherosclerotic lesions, suggesting a link between the amount of NC and their predisposition to rupture [3]. In fact, the area of necrotic core in thin capped fibroatheromas (TCFA) is $1.6 \pm 1.8 \mathrm{~mm}^{2}$ and in ruptured plaques is $2.2 \pm 1.9 \mathrm{~mm}^{2}$ respectively [3].

Anthropometric measurements and conventional $\mathrm{CV}$ risk factors relate to the risk of subsequent $\mathrm{CV}$ events as demonstrated by the original Framingham cohort, and more recently by the INTERHEART multiethnic study on the predictors of the first myocardial infarction (MI) $[4,5]$. Notwithstanding these observations, accurate prediction of major coronary events on an individual patient level, as opposed to population based studies, remains challenging. Therefore, there is an interest in additional markers of patient vulnerability that would enhance precision of risk estimation beyond that afforded by the Framingham risk score or other conventional risk assessment tools. The ability to quantify NC in vivo by the intravascular ultrasound radiofrequency (IVUS-RF) data analysis offers the opportunity to provide unique information about plaque type to enhance the precision of clinical and laboratory variables used to assess $\mathrm{CV}$ risk. Although the ultimate validity of this measurement will require very large and long-term natural history studies, the first step is to examine the relationship between patient derived variables and $\mathrm{NC}$ and extension of coronary atheroma. Accordingly, we sought to explore in vivo the relationship between patient demographics, anthropometric measures, $\mathrm{CV}$ risk factors, soluble biomarkers and plaque composition (percentage of necrotic core) or its overall size (percentage atheroma volume).

\section{Methods}

Study design

The Integrated Biomarkers and Imaging Study-2 trial has been published elsewhere [6]. Briefly, it was an international, multicenter, randomized, double blind, placebo-controlled study in patients with confirmed CHD. Institutional review boards at each center approved the protocol, and patients provided written informed consent. Within 10 days of cardiac catheterization, eligible patients who were clinically stable were randomized to oral doses of darapladib EC $160 \mathrm{mg}$ (GlaxoSmithKline) or placebo once daily (1:1 ratio) for the 12 months treatment period.

\section{Patient population}

Patients 18 years of age or older undergoing cardiac catheterization for acute coronary syndrome (ACSnon-ST-elevation and ST-elevation MI) or non-ACS (e.g, chronic stable angina or troponin-negative resting chest pain) were eligible. The protocol specified that $50 \%$ of randomized patients were to have troponinpositive ACS. The randomization was stratified according to ACS status and center. Key exclusion criteria were planned surgical revascularization, stroke in the past 6 months, chronic hepatic disorder or abnormal ALT, bilirubin (ALT $>2.5$ or bilirubin $>$ 1.5 upper limit of normal), serum creatinine $>2.0 \mathrm{mg}$ / $\mathrm{dL}$, blood pressure $>160 / 100 \mathrm{mmHg}$, poorly controlled diabetes mellitus $\left(\mathrm{HbA}_{1 \mathrm{c}}>10 \%\right)$, severe heart failure or left ventricular ejection fraction $<30 \%$, and 
current life-threatening condition. Patients were ineligible if angiography demonstrated left main coronary stenosis $>50 \%$ or if coronary anatomy was inappropriate for IVUS.

\section{IVUS imaging}

The ECG-gated IVUS-RF acquisition was performed using EagleEye catheter (20 MHz) at pullback speed of $0.5 \mathrm{~mm} / \mathrm{sec}$. The quantitative IVUS analysis was performed by the Core Imaging Laboratory (Cardialysis, Rotterdam, The Netherlands) using customized software (pcVH 2.1, Volcano Corporation). The analyst selected the region of interest flanked by the presence of easily identifiable anatomical landmarks.

Vessel and lumen area data were obtained for every cross-section throughout the region of interest by semiautomatic planimetry of the leading edges of the luminal and external elastic membrane borders. The composition of coronary atheroma was assessed using spectral analysis of backscatter RF signals (Fig. 1). Necrotic core was identified with an autoregressive classification system that showed a sensitivity and specificity of 92 and $97 \%$ for detection of necrotic core, respectively. To assess intra- and interobserver variability of necrotic core measurements, 20 patients from the current study (2,465 frames) were analyzed twice by two different analysts. The mean absolute difference for necrotic core area was
$0.01 \mathrm{~mm}^{2}$ (SD 0.06) for the intra-observer, and $0.02 \mathrm{~mm}^{2}$ (SD 0.08) for the inter-observer variability, respectively.

\section{Study end point definitions (IVUS-RF)}

Atheroma area contains both atherosclerotic plaque and media. This was obtained after planimetry was completed at the lumen/plaque boundary and at the media/adventitia boundary in each cross-section forming the region of interest. Percent atheroma volume was derived by dividing the total atheroma volume by the total vessel volume and multiplying by 100.

The necrotic core area was automatically obtained in each cross-section forming the region of interest using dedicated software (pcVH 2.1, Volcano Therapeutics). Necrotic core values were expressed in $\mathrm{mm}^{2}$. In addition, the percentage of necrotic core was calculated as the percentage of the total tissue type components.

\section{Biomarkers}

Plasma hsCRP was measured as described previously [7]. Plasma Lp-PLA ${ }_{2}$ activity was measured by a colorimetric method [7]. Other biomarkers (IL-6, MPO, ICAM-1, and MMP-9 activity) were assayed using commercially available kits. Oxidized

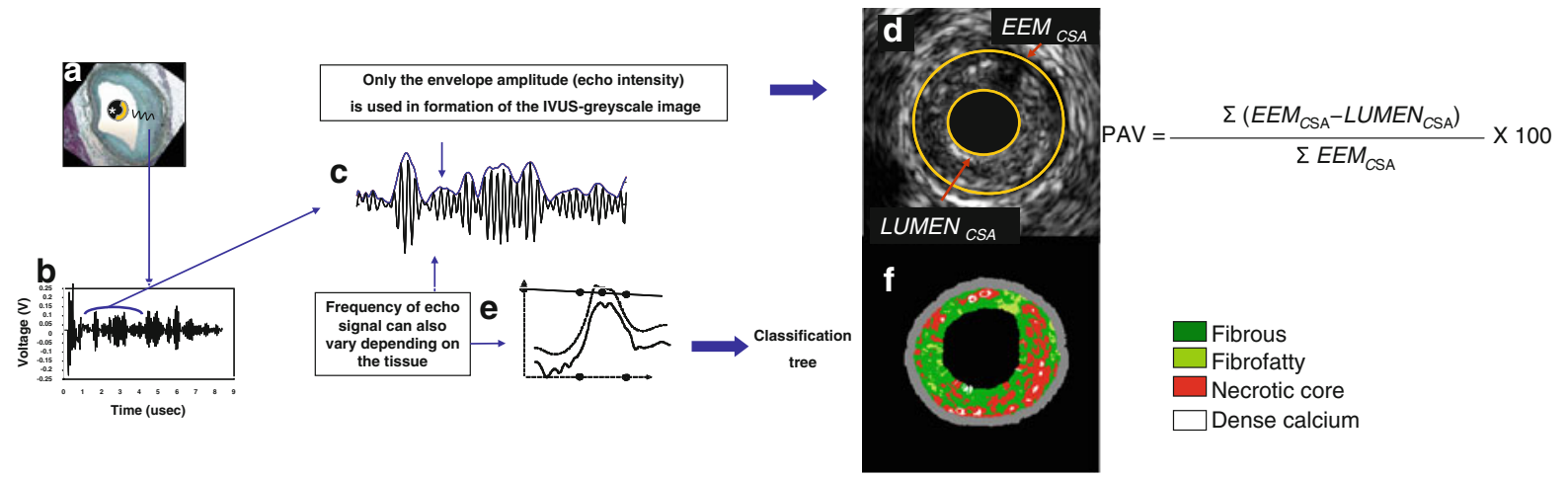

Fig. 1 The ultrasound signal is generated in a piezoelectric crystal (asterisk) that transmits and receives sound waves (a). Ultrasound reflected by the tissue deforms crystal generating radiofrequency (RF) signal (b). Greyscale IVUS is derived from the amplitude of RF signal, discarding information beneath the peaks of the signal (c). Changes in the electric field of the piezoelectric crystal caused by ultrasound reflection is used to generate a grey-tone image (d). IVUS-RF analysis uses several additional spectral parameters to identify four plaque components (e). Plaque components that are identified are dense calcium (white), fibrous (green), fibro-fatty (greenishyellow) and necrotic core (red) (f). PAV percentage atheroma volume, EEM external elastic membrane, CSA cross-sectional area 
phospholipid content per particle of apoB (oxPL/ apoB) was measured using murine monoclonal antibody E06 as described [8]. Platelet biomarkers were measured in plasma (P-selectin, CD40L) [7].

Endothelial function

Endothelial function was assessed using peripheral artery tonometry (PAT). PAT is a noninvasive method that uses automated technology to obtain continuous data monitoring of the peripheral arterial pulse waveform by use a finger-mounted pneumatic sensor (Endo-PAT 2000, Itamar Medical). The magnitude of the waveform is dependent on vascular compliance. Endothelial function is assessed by changes in compliance after period of ischemia followed by reperfusion. A ratio of the amplitude prior and after occlusion is calculated and corrected for baseline value and a second sensor is used as a control on the non-occluded extremity.

\section{Statistical analysis}

Necrotic core as a percent of VH plaque and percent atheroma volume (both baseline and change from baseline) were the dependent variables explored in these analyses. A total of 39 covariates were considered in the univariate regression analyses. In addition, treatment group and baseline value were considered in the analyses of change from baseline. All class variables, except gender, were coded $[0,1]$ with 0 for absence or 1 for presence. Gender was coded 0 for females and 1 for males. The set of variables with a $p$ value of $\leq 0.10$ in the univariate regression analyses were included in the multivariate regression analyses. Both backward selection and forward selection were used, and the entry criterion and stay criterion were set to 0.05 .

Statistical analyses were performed with use of SAS V9.1.3.

\section{Results}

Between November 16th, 2005 and August 16th, 2006, 330 patients were enrolled.

There are 239 subjects with a value for change from baseline in \% necrotic core and there are 262 subjects with a value for change from baseline in $\%$ atheroma volume. Table 1, which has been published previously characterizes the population and is based on the ITT population $(\mathrm{N}=323)$ [6]. Mean length of the IVUS pullbacks was $50.3 \pm 16.8 \mathrm{~mm}$.

Univariate association between baseline characteristics and plaque morphology

The list of variables (only those with a $p$ value $<0.10)$ and their univariate association with percentage necrotic core (PNC) area and percentage atheroma volume (PAV) is shown in Tables 2 and 3.

Multivariate association between baseline characteristics and plaque morphology

In the multivariate analysis, at baseline, creatinine had a positive, whereas baseline mean lumen diameter and myeloperoxidase a negative, independent association with PNC. Age, GFR $<60$, HbA1c, previous percutaneous or surgical coronary revascularisation and baseline \% diameter stenosis were all positively associated with baseline PAV, whilst ACS had a negative association (Table 4).

Multivariate association between baseline characteristics and change from baseline in plaque morphology

The variables associated with a decreased PNC from baseline were darapladib, ACS and a large content of $\mathrm{NC}$ at baseline, while variables associated with an increase in PNC were previous stroke and \% diameter stenosis at baseline. The variables associated with a decrease in PAV from baseline were waist circumference, statin use, CD40L and baseline PAV, while the only variable associated with an increase in PAV was diastolic blood pressure (Table 4).

\section{Discussion}

In non-culprit vessels, large baseline and necrotic core rich plaques are associated with a decrease in percentage of necrotic core at 1 year. Patients with acute coronary syndrome are more likely to have a decrease in necrotic core. In this analysis, and after adjustment for other variables, treatment with darapladib was associated with a decrease in necrotic 
Table 1 Baseline Characteristics

\begin{tabular}{|c|c|c|}
\hline & $\begin{array}{l}\text { Placebo } \\
(\mathrm{n}=151)\end{array}$ & $\begin{array}{l}\text { Darapladib } \\
(\mathrm{n}=172)\end{array}$ \\
\hline \multicolumn{3}{|l|}{ Clinical characteristics } \\
\hline Age (y) & $57.3 \pm 10.9$ & $59.4 \pm 9.8$ \\
\hline Males (n, \%) & $126(83)$ & $140(81)$ \\
\hline Body-mass index $\left(\mathrm{kg} / \mathrm{m}^{2}\right)$ & $27.8 \pm 3.8$ & $27.5 \pm 4.0$ \\
\hline Diabetes mellitus (n, \%) & $22(15)$ & $22(13)$ \\
\hline Hypertension (n, \%) & $89(59)$ & $115(67)$ \\
\hline $\begin{array}{l}\text { Low HDL cholesterol } \\
(<40 \mathrm{mg} / \mathrm{dL})(\mathrm{n}, \%)\end{array}$ & $40(26)$ & $45(26)$ \\
\hline Hypercholesterolemia (n, \%) & $95(63)$ & $108(63)$ \\
\hline \multicolumn{3}{|l|}{ Current smoker (n, \%) } \\
\hline Prior medical history (n, \%) & $57(38)$ & $64(37)$ \\
\hline Prior myocardial infarction & $49(32)$ & $51(29)$ \\
\hline $\begin{array}{l}\text { Prior coronary } \\
\text { revascularization }\end{array}$ & $47(31)$ & $50(29)$ \\
\hline Peripheral artery disease & $7(5)$ & $17(10)$ \\
\hline Prior stroke & $3(2)$ & $4(2)$ \\
\hline \multicolumn{3}{|l|}{ Index hospitalization (n, \%) } \\
\hline ACS & $74(49)$ & $87(51)$ \\
\hline STEMI & $35(23)$ & $40(23)$ \\
\hline Non-STEMI & $39(26)$ & $47(27)$ \\
\hline $\begin{array}{l}\text { PCI during index } \\
\text { hospitalization }\end{array}$ & $122(81)$ & $130(76)$ \\
\hline \multicolumn{3}{|c|}{ Cardiovascular medications at randomization $(\mathrm{n}, \%)$} \\
\hline Aspirin & $138(91)$ & $149(87)$ \\
\hline Clopidogrel or ticlopidine & $122(81)$ & $136(79)$ \\
\hline Any antiplatelet medication & $150(>99)$ & $170(99)$ \\
\hline ACE inhibitors or ARBs & $88(58)$ & $101(59)$ \\
\hline Beta-blockers & $119(79)$ & $138(80)$ \\
\hline Statins & $134(89)$ & $157(91)$ \\
\hline \multicolumn{3}{|l|}{ Laboratory values } \\
\hline \multicolumn{3}{|l|}{ Cholesterol (mg/dL) } \\
\hline Total & $187.3 \pm 47.6$ & $182.3 \pm 43.2$ \\
\hline LDL & $108.2 \pm 41.4$ & $103.6 \pm 37.4$ \\
\hline HDL & $46.8 \pm 11.2$ & $48.0 \pm 12.4$ \\
\hline \multicolumn{3}{|l|}{ Triglycerides $(\mathrm{mg} / \mathrm{dL})$} \\
\hline Median & 141 & 136 \\
\hline IQR & 97-202 & $96-193$ \\
\hline \multicolumn{3}{|l|}{ hsC-reactive protein (mg/L) } \\
\hline geometric mean & 2.4 & 2.4 \\
\hline $95 \% \mathrm{CI}$ & $1.9,3.1$ & $1.9,3.0$ \\
\hline \multicolumn{3}{|l|}{ Lp-PLA ${ }_{2}$ activity $(\mu \mathrm{mol} / \mathrm{min} / \mathrm{L})$} \\
\hline geometric mean & 159 & 160 \\
\hline $95 \% \mathrm{CI}$ & 152,167 & 153,167 \\
\hline Blood pressure & & \\
\hline
\end{tabular}

Table 1 continued

\begin{tabular}{|c|c|c|}
\hline & $\begin{array}{l}\text { Placebo } \\
(\mathrm{n}=151)\end{array}$ & $\begin{array}{l}\text { Darapladib } \\
(\mathrm{n}=172)\end{array}$ \\
\hline Systolic (mm Hg) & $125.7 \pm 16.9$ & $128.0 \pm 16.1$ \\
\hline Diastolic (mmHg) & $75.2 \pm 10.1$ & $75.6 \pm 9.9$ \\
\hline \multicolumn{3}{|l|}{ Study vessel ${ }^{\mathrm{a}}-$ no. $(\%)$} \\
\hline LAD & $44(36)$ & $56(39)$ \\
\hline LCX & $32(26)$ & $37(26)$ \\
\hline RCA & $45(37)$ & $51(35)$ \\
\hline Diameter stenosis $^{\mathrm{b}}(\%)$ & $28.0(10.5)$ & $26.6(10.3)$ \\
\hline Mean lumen diameter ${ }^{\mathrm{b}}(\mathrm{mm})$ & $2.9 \pm 0.5$ & $3.0 \pm 0.6$ \\
\hline
\end{tabular}

Values are presented as mean \pm SD unless otherwise specified; To convert to $\mathrm{mmol} / \mathrm{L}$ multiply values of cholesterol by 0.02586 and triglycerides by 0.0113

$P C I$ percutaneous coronary intervention, ACS acute coronary syndromes

a Imaging evaluable population: placebo 121 patients; darapladib 146 patients

b Quantitative coronary angiography: placebo 121 patients; darapladib 144 patients

core, but failed to be associated with a decrease in percentage atheroma volume. On the contrary, statin use was only associated with a decrease in percentage atheroma volume. Thus, patients may need to receive both drugs to target overall plaque regression and specifically necrotic core regression.

Our current understanding of plaque biology suggests that $\sim 60 \%$ of clinically evident plaque rupture (i.e. acute coronary syndromes) originates within an inflamed thin-capped fibroatheroma (TCFA) [9]. TCFAs are coronary plaques that contain the largest necrotic core. In living patients, Hong et al. reported the frequency and distribution of TCFA identified by virtual histology intravascular ultrasound in acute coronary syndrome $(\mathrm{ACS}=105$ pts) and stable angina pectoris $(\mathrm{SAP}=107 \mathrm{pts})$ in a 3 -vessel IVUS-VH study. There were $2.5 \pm 1.5$ in ACS and $1.7 \pm 1.1$ in SAP TCFAs per patient, $p<0.001$. Presentation with ACS was the only independent predictor for multiple IVUS derivedTCFA $(p=0.011)$. Thus, in patients with ACS not only are necrotic core rich plaques more likely to be present, but they are also present in higher numbers when compared to patients with stable angina.

A pathological study has shown that Lp-PLA2 staining was nearly absent in pathologic intimal thickening plaques; while in complex lesions, such as 
Table 2 List of variables (only with a $p$ value $<0.10$ ) and their univariate association with percentage necrotic core

\begin{tabular}{|c|c|c|}
\hline Parameter & $\begin{array}{l}\text { Parameter estimate } \\
90 \% \text { CI }\end{array}$ & $p$ value \\
\hline \multicolumn{3}{|c|}{ Cross-sectional analysis at baseline-percentage necrotic core } \\
\hline Waist circumference & $0.063(0.003,0.123)$ & 0.085 \\
\hline Netherlands/Belgium & $4.733(2.143,7.323)$ & 0.003 \\
\hline Czech Republic/Poland & $4.030(1.351,6.708)$ & 0.014 \\
\hline $\begin{array}{l}\text { Germany/Austria/ } \\
\text { Denmark }\end{array}$ & -0) & 0.025 \\
\hline Norway & $4.244(0.770,7.718)$ & 0.045 \\
\hline Spe & 3.9 & 0.072 \\
\hline GFR $<60$ & $2.429(0.020,4.838)$ & 0.097 \\
\hline Systolic blood pressure & $0.047(0.006,0.087)$ & 0.057 \\
\hline Hypercholesterolemia & $-1.474(-2.825,-0.122)$ & 0.073 \\
\hline Creatinine (nlog) & $5.758(2.717,8.799)$ & 0.002 \\
\hline Mean lumen diameter & $-2.449(-3.755,-1.144)$ & 0.002 \\
\hline Myeloperoxidase & $-0.932(-1.773,-0.091)$ & 0.068 \\
\hline \multicolumn{3}{|c|}{ Predictors of change from baseline-percentage necrotic core } \\
\hline $\mathrm{ACS}$ & $-1.961(-3.791,-0.132)$ & 0.078 \\
\hline Statin & $-3.196(-6.084,-0.309)$ & 0.069 \\
\hline Previous stroke & $6.040(0.191,11.888)$ & 0.090 \\
\hline oxPL(n log) & $1.191(0.026,2.355)$ & 0.093 \\
\hline $\begin{array}{l}\text { Circulating p-selection (n } \\
\log \text { ) }\end{array}$ & $-2.935(-5.340,-0.529)$ & 0.045 \\
\hline Previous PCI or CABG & $2.211(0.269,4.154)$ & 0.061 \\
\hline$\%$ Diameter stenosis & $0.103(0.014,0.191)$ & 0.057 \\
\hline Baseline $\%$ necrotic core & $-0.561(-0.677,-0.445)$ & $<0.001$ \\
\hline Darapladib & $-2.038(-3.872,-0.204)$ & 0.068 \\
\hline
\end{tabular}

thin-cap fibroatheromas and ruptured plaques, an intense Lp-PLA2 expression within necrotic cores and surrounding macrophages, including those in the fibrous cap, was seen [10]. In animal studies, reduced development of advanced coronary atherosclerosis has been seen in diabetic and hypercholesterolemic swine with the use of selective lipoprotein-associated phospholipase A2 inhibitors (i.e. darapladib) [11]. Specifically, darapladib treatment resulted in a considerable decrease in plaque area and necrotic core area, and reduced medial destruction, resulting in fewer lesions with an unstable phenotype.

Necrotic core and cardiovascular risk factors in pathological studies

Prior attempts to correlate patient characteristics with plaque morphology assessed during post-mortem
Table 3 List of variables (only with a $p$ value $<0.10$ ) and their univariate association with percentage atheroma volume

\begin{tabular}{lll}
\hline Parameter & $\begin{array}{l}\text { Parameter } \\
\text { estimate } 90 \% \mathrm{CI}\end{array}$ & $p$ value \\
\hline
\end{tabular}

Cross-sectional analysis at baseline-percentage atheroma volume

$\begin{array}{lcr}\text { Age } & 0.240(0.140,0.339) & <0.001 \\ \text { Smoking } & -3.718(-5.790,-1.646) & 0.003 \\ \text { ACS } & -3.733(-5.735,-1.731) & 0.002 \\ \text { GFR }<60 & 5.541(1.612,9.470) & 0.021 \\ \text { SBP }( & 0.110(0.047,0.173) & 0.004 \\ \text { IL-6 (n log) } & 1.103(0.107,2.099) & 0.069 \\ \text { OxPL (n log) } & 1.550(0.251,2.850) & 0.050 \\ \text { HbA1c (n log) } & 15.075(6.445,23.705) & 0.004 \\ \text { Previous PCI or CABG } & 4.770(2.634,6.905) & 0.003 \\ \text { Creatinine (n log) } & 6.720(1.950,11.491) & 0.021 \\ \text { \% Diameter stenosis } & 0.335(0.245,0.426) & <0.001 \\ \text { Endothelial function } & 3.721(0.856,6.587) & 0.033 \\ \text { MMP-9 (n log) } & -1.331(-2.630,-0.031) & 0.092\end{array}$

Predictors of change from baseline-percentage atheroma volume

Waist circumference $\quad-0.048(-0.085,-0.012) \quad 0.031$

Czech Republic/Poland $2.933(1.250,4.616) \quad 0.004$

$\begin{array}{lll}\text { Statin use } & -2.156(-3.509,-0.803) & 0.009\end{array}$

CD40L (n log) $\quad-0.776(-1.294,-0.257) \quad 0.014$

DBP $0.078(0.037,0.119) \quad 0.002$

Myeloperoxidase $(\mathrm{n} \log ) \quad 0.529(0.014,1.043) \quad 0.091$

Baseline \% atheroma $\quad-0.095(-0.135,-0.056)<0.001$ volume

GFR Glomerular filtration rate, oxPL Oxidized phospholipids, $P C I$ percutaneous coronary intervention, $C A B G$ coronary artery bypass graft, $A C S$ acute coronary syndrome, $S B P$ systolic blood pressure, $I L$ interleukin, HbAlc Hemoglobin A1c, MMP Matrix metalloproteinase, DBP diastolic blood pressure

examination are limited by selection bias, (only patients with fatal events due to coronary or no coronary causes are included) and often post-mortem ascertainment of laboratory values. Nevertheless, history of smoking was associated with evidence of acute coronary thrombosis (OR 3.6, $p=0.004$ ) whilst low HDL-cholesterol levels were associated with plaque rupture (odds ratio for each additional milligram per deciliter, 1.01) [12]. Diabetes was shown to be associated with larger necrotic core and increased macrophage content consistent with the clinically observed increased risk of $\mathrm{CV}$ events in these patients [13]. The differences with the current 
Table 4 List of variables $(p \leq 0.05)$ and their multivariate association with percentage necrotic core and percentage atheroma volume

\begin{tabular}{|c|c|c|}
\hline Parameter & $\begin{array}{l}p \text { value estimate } \\
(95 \% \mathrm{CI})\end{array}$ & Variable \\
\hline \multicolumn{3}{|c|}{ Cross-sectional analysis at baseline-percentage necrotic core } \\
\hline Creatinine $(\mu \mathrm{mol} / \mathrm{L}-\mathrm{n} \log )$ & $5.7(1.8,9.6)$ & 0.004 \\
\hline $\begin{array}{l}\text { Mean lumen diameter } \\
\quad(\mathrm{mm})\end{array}$ & $-2.3(-3.8,-0.79)$ & 0.003 \\
\hline Myeloperoxidase (n log) & $-1.2(-2.2,-0.15)$ & 0.025 \\
\hline \multicolumn{3}{|c|}{ Predictors of change from baseline-percentage necrotic core } \\
\hline Darapladib & $-2.1(-4.0,-0.22)$ & 0.029 \\
\hline Acute coronary syndrome & $-2.9(-4.8,-1.0)$ & 0.003 \\
\hline Previous stroke & $8.4(2.6,14.2)$ & 0.005 \\
\hline $\begin{array}{l}\text { Baseline \% diameter } \\
\text { stenosis }\end{array}$ & $0.10(0.007,0.19)$ & 0.035 \\
\hline Baseline \% NC & $-0.56(-0.69,-0.42)$ & $<0.001$ \\
\hline \multicolumn{3}{|c|}{$\begin{array}{l}\text { Cross-sectional analysis at baseline-percentage atheroma } \\
\text { volume }\end{array}$} \\
\hline Age (y) & $0.12(0.001,0.24)$ & 0.049 \\
\hline Acute coronary syndrome & $-2.6(-4.9,-0.29)$ & 0.027 \\
\hline $\mathrm{GFR}<60 \mathrm{ml} / \mathrm{min}$ & $5.1(0.90,9.3)$ & 0.017 \\
\hline HbA1c (n log) & $12.4(2.9,21.9)$ & 0.011 \\
\hline Previous PCI or $\mathrm{CABG}$ & $3.1(0.66,5.6)$ & 0.013 \\
\hline $\begin{array}{l}\text { Baseline \% diameter } \\
\text { stenosis }\end{array}$ & $0.33(0.22,0.44)$ & $<0.001$ \\
\hline \multicolumn{3}{|c|}{$\begin{array}{l}\text { Predictors of change from baseline-percentage atheroma } \\
\text { volume }\end{array}$} \\
\hline Waist circumference $(\mathrm{cm})$ & $-0.05(-0.09,-0.004)$ & 0.032 \\
\hline Statin Use & $-2.0(-3.6,-0.42)$ & 0.013 \\
\hline CD40L (pg/ml) & $-0.74(-1.3,-0.15)$ & 0.014 \\
\hline $\begin{array}{l}\text { Diastolic blood pressure } \\
\quad(\mathrm{mmHg})\end{array}$ & $0.09(0.04,0.14)$ & $<0.001$ \\
\hline $\begin{array}{l}\text { Baseline } \% \text { atheroma } \\
\text { volume }\end{array}$ & $-0.09(-0.14,-0.04)$ & $<0.001$ \\
\hline
\end{tabular}

study may stem from the fact that our observations focused on non-culprit vessels. In addition, the current algorithm for spectral analysis of IVUS-RF is unable to detect thrombus and lacks precision to detect inflammatory cell content. Post-mortem measurement of HDL-cholesterol is also fraught with potential confounding factors.

Plaque size by intravascular imaging and its relationship with $\mathrm{CV}$ risk factors

Several CV risk factors such as male gender, body mass index (BMI), diabetes and prior coronary revascularization have been found to be strong predictors of atheroma volume measured by conventional IVUS. As shown by Nicholls et al. atheroma volume in women in secondary prevention trials is smaller, even in the presence of more risk factors [14]. Our study confirms some of these observations showing an independent association of $\mathrm{HbA1C}$ and prior coronary revascularization with IVUS measurements. Diabetes per se was not an independent predictor and this is possibly related to the low number of diabetics enrolled in the current study. Obesity is an important but complex contributor to $\mathrm{CV}$ morbidity and mortality [15]. Waist circumference, and simple measures of visceral (abdominal) obesity, has a superior predictive value for the presence of CHD or the risk of MI, compared to that of BMI [16]. The large multi-ethnic INTERHEART study showed a significant relationship between waist circumference or waist-to-hip ratio and the risk of first MI, even after full adjustment for other risk factors [5]. Furthermore, patients with low BMI and increased waist circumference have an increased 1-year mortality [17]. In our study, patients with large waist circumference were independently associated with percentage atheroma volume reduction after 1 year.

Despite favourable effects of cholesterol-lowering therapy with statins in primary and secondary prevention, a single measurement of serum lipids did not correlate with IVUS measurements of percentage atheroma volume or percentage necrotic core in univariate or multivariate analysis. These findings are consistent with those reported by others regarding conventional IVUS measures and do not contradict halting plaque progression or even its regression with intensive LDL cholesterol lowering.

In contrast to lipid measurements, renal dysfunction was related to both larger percentage necrotic core and larger percentage atheroma volume. Anavekar et al. [18] have described that even mild renal disease should be considered a major risk factor for cardiovascular complications after an MI. We could hypothesize that the underlying cause of these events are necrotic core-rich large plaques.

It is noteworthy that diastolic blood pressure was shown to be independently associated with plaque progression by IVUS, and therapeutic intervention(s) aimed at lowering blood pressure below current guideline mandated thresholds, may retard progression of atherosclerosis and reduce CV events [19]. 
Study limitations

This study is a post-hoc analysis that has a number of limitations. First, the sample size was small. Second, the measurements of biomarkers that entered into the model do not reflect chronic circulating levels, as $50 \%$ of patients presented with ACS, which transiently alters levels of inflammatory biomarkers. In addition, our data indicate that ACS status is not associated with necrotic core size when assessed in non-culprit vessels. Although pan-coronary inflammation was reported in ACS patients, IVUS methodology is not well suited to measure such endpoints. Third, some of the measurements are confounded by concomitant treatments. Fourth, we wish to emphasize that all IVUS studies are limited to the analysis of a relatively short segment of coronary arterial tree that does not fully reflect disease characteristics elsewhere.

Although independently treatment with darapladib was associated with a decrease in percentage necrotic core and statin use was only associated with a decrease in percentage atheroma volume, the interaction factor between statins and darapladib for the relationship between changes in necrotic core and percentage atheroma volume has not been assessed.

\section{Conclusions}

In non-culprit vessels, large baseline and necrotic core rich plaques are associated with a decrease in percentage of necrotic core at 1 year. Patients with acute coronary syndrome are more likely to have a decrease in necrotic core. In these analyses and after adjustment for other variables, treatment with darapladib was associated with a decrease in percentage necrotic core, but failed to be associated with a decrease in percentage atheroma volume. On the contrary, statin use was only associated with a decrease in percentage atheroma volume.

Funding source This study was funded by a research grant from GlaxoSmithKline.

Conflict of interest Jennifer Shannon is employee of GlaxoSmithKline. The rest of the Authors do not have any conflict of interest to declare.
Open Access This article is distributed under the terms of the Creative Commons Attribution Noncommercial License which permits any noncommercial use, distribution, and reproduction in any medium, provided the original author(s) and source are credited.

\section{Appendix}

Core Laboratories: Imaging (Cardialysis, Rotterdam, The Netherlands).

Participating Centers (number of patients enrolled): Austria: Hanusch Krankenhaus, Georg Gaul (6). Belgium: Centre Hospitalier Universitaire Sart-Tilman, Victor Legrand (10); ZNA Campus Middelheim, Stefan Verheye (25); Cardiovascular Center, Aalst, William Wijns (14). Czech Republic: V̌̌eobecná Fakultní Nemocnice, Michael Aschermann (23). Denmark: Skejby University Hospital, Hans Erik Bøtker (18). Germany: West German Heart Center, Raimund Erbel (7); Kerckhoff Klinik, Christian Hamm (7); Universitätsklinikum Heidelberg, Stefan Hardt, Helmut Kücherer (1); Universitätsklinikum München, Volker Klauss (14), Universitätsklinikum Ulm, Wolfgang Koenig (9); Segeberger Kliniken, Gert Richardt (3). The Netherlands: Medisch Spectrum Twente, Clemens von Birgelen (14); Medisch Centrum Leeuwarden, Adrianus Johannes van Boven (12); Catharina Hospital and Catherine R\&D, Herman Rolf Michels (14), Erasmus Medical Center, Patrick Serruys (20); Medisch Centrum Rijnmond Zuid, Pieter Smits (11). Norway: Haukeland Sykehus, Oyvind Bleie (20). Poland: Upper Silesian Heart Center, Pawel Buszman (40); Szpital Uniwersytecki, Dariusz Dudek (19). Spain: Hospital Marques de Valdecilla, Thierry Colman (9); Hospital Clinico San Carlos, Carlos Macaya (9). Switzerland: Kantonsspital Luzern, Paul Erne (25).

\section{References}

1. Virmani R, Kolodgie FD, Burke AP, Farb A, Schwartz SM (2000) Lessons from sudden coronary death: a comprehensive morphological classification scheme for atherosclerotic lesions. Arterioscler Thromb Vasc Biol 20(5): 1262-1275 
2. Davies MJ (1992) Anatomic features in victims of sudden coronary death. Coronary artery pathology. Circulation 85(1 Suppl):I19-I24

3. Cheruvu PK, Finn AV, Gardner C, Caplan J, Goldstein J, Stone GW, Virmani R, Muller JE (2007) Frequency and distribution of thin-cap fibroatheroma and ruptured plaques in human coronary arteries: a pathologic study. J Am Coll Cardiol 50(10):940-949

4. Yusuf S, Hawken S, Ounpuu S, Dans T, Avezum A, Lanas F, McQueen M, Budaj A, Pais P, Varigos J, Lisheng L (2004) Effect of potentially modifiable risk factors associated with myocardial infarction in 52 countries (the INTERHEART study): case-control study. Lancet 364(9438):937-952. doi:10.1016/S0140-6736(04)17018-9

5. Yusuf S, Hawken S, Ounpuu S, Bautista L, Franzosi MG, Commerford P, Lang CC, Rumboldt Z, Onen CL, Lisheng L, Tanomsup S, Wangai P Jr, Razak F, Sharma AM, Anand SS (2005) Obesity and the risk of myocardial infarction in 27, 000 participants from 52 countries: a case-control study. Lancet 366(9497):1640-1649. doi:10.1016/S01406736(05)67663-5

6. Serruys PW, Garcia-Garcia HM, Buszman P, Erne P, Verheye S, Aschermann M, Duckers H, Bleie O, Dudek D, Botker HE, von Birgelen C, D'Amico D, Hutchinson T, Zambanini A, Mastik F, van Es GA, van der Steen AF, Vince DG, Ganz P, Hamm CW, Wijns W, Zalewski A (2008) Effects of the direct lipoprotein-associated phospholipase $\mathrm{A}(2)$ inhibitor darapladib on human coronary atherosclerotic plaque. Circulation 118(11):1172-1182. doi:10.1161/CIRCULATIONAHA.108.771899

7. Mohler ER 3rd, Ballantyne CM, Davidson MH, Hanefeld M, Ruilope LM, Johnson JL, Zalewski A (2008) The effect of darapladib on plasma lipoprotein-associated phospholipase A2 activity and cardiovascular biomarkers in patients with stable coronary heart disease or coronary heart disease risk equivalent: the results of a multicenter, randomized, double-blind, placebo-controlled study. J Am Coll Cardiol 51(17):1632-1641. doi:10.1016/j.jacc.2007.11.079

8. Lindner JR, Dayton PA, Coggins MP, Ley K, Song J, Ferrara K, Kaul S (2000) Noninvasive imaging of inflammation by ultrasound detection of phagocytosed microbubbles. Circulation 102(5):531-538

9. Virmani R, Burke AP, Farb A, Kolodgie FD (2006) Pathology of the vulnerable plaque. J Am Coll Cardiol 47(8 Suppl):C13-C18. doi:10.1016/j.jacc.2005.10.065

10. Kolodgie FD, Burke AP, Skorija KS, Ladich E, Kutys R, Makuria AT, Virmani R (2006) Lipoprotein-associated phospholipase A2 protein expression in the natural progression of human coronary atherosclerosis. Arterioscler Thromb Vasc Biol 26(11):2523-2529. doi:10.1161/01. ATV.0000244681.72738.bc
11. Wilensky RL, Shi Y, Mohler ER 3rd, Hamamdzic D, Burgert ME, Li J, Postle A, Fenning RS, Bollinger JG, Hoffman BE, Pelchovitz DJ, Yang J, Mirabile RC, Webb CL, Zhang L, Zhang P, Gelb MH, Walker MC, Zalewski A, Macphee CH (2008) Inhibition of lipoprotein-associated phospholipase A2 reduces complex coronary atherosclerotic plaque development. Nat Med 14(10):1059-1066. doi: $10.1038 / \mathrm{nm} .1870$

12. Burke AP, Farb A, Malcom GT, Liang YH, Smialek J, Virmani R (1997) Coronary risk factors and plaque morphology in men with coronary disease who died suddenly. N Engl J Med 336(18):1276-1282

13. Burke AP, Kolodgie FD, Zieske A, Fowler DR, Weber DK, Varghese PJ, Farb A, Virmani R (2004) Morphologic findings of coronary atherosclerotic plaques in diabetics: a postmortem study. Arterioscler Thromb Vasc Biol 24(7): 1266-1271

14. Nicholls SJ, Wolski K, Sipahi I, Schoenhagen P, Crowe T, Kapadia SR, Hazen SL, Tuzcu EM, Nissen SE (2007) Rate of progression of coronary atherosclerotic plaque in women. J Am Coll Cardiol 49(14):1546-1551. doi:10. 1016/j.jacc.2006.12.039

15. Barrett-Connor EL (1985) Obesity, atherosclerosis, and coronary artery disease. Ann Intern Med 103(6 (Pt 2)): 1010-1019

16. Onat A, Avci GS, Barlan MM, Uyarel H, Uzunlar B, Sansoy V (2004) Measures of abdominal obesity assessed for visceral adiposity and relation to coronary risk. Int $\mathrm{J}$ Obes Relat Metab Disord 28(8):1018-1025. doi:10.1038/ sj.ijo

17. Zeller M, Steg PG, Ravisy J, Lorgis L, Laurent Y, Sicard P, Janin-Manificat L, Beer JC, Makki H, Lagrost AC, Rochette L, Cottin Y (2008) Relation between body mass index, waist circumference, and death after acute myocardial infarction. Circulation 118(5):482-490. doi:10.1161/CIRCULATION AHA.107.753483

18. Anavekar NS, McMurray JJ, Velazquez EJ, Solomon SD, Kober L, Rouleau JL, White HD, Nordlander R, Maggioni A, Dickstein K, Zelenkofske S, Leimberger JD, Califf RM, Pfeffer MA (2004) Relation between renal dysfunction and cardiovascular outcomes after myocardial infarction. N Engl J Med 351(13):1285-1295. doi:10.1056/ NEJMoa041365

19. Nissen SE, Tuzcu EM, Libby P, Thompson PD, Ghali M, Garza D, Berman L, Shi H, Buebendorf E, Topol EJ (2004) Effect of antihypertensive agents on cardiovascular events in patients with coronary disease and normal blood pressure: the CAMELOT study: a randomized controlled trial. JAMA 292(18):2217-2225 